\title{
Socioemotional selectivity and mental health among trauma survivors in old age
}

Derek M. Isaacowitz

Timothy B. Smith

Brigham Young University, tbs@byu.edu

Laura L. Carstensen

Follow this and additional works at: https://scholarsarchive.byu.edu/facpub

Part of the Counseling Psychology Commons

\section{Original Publication Citation}

Isaacowitz, D. M., Smith, T. B., \& Carstensen, L. L. (2003). Socioemotional selectivity and mental health among trauma survivors in old age. Ageing International, 28, 181-199.

\section{BYU ScholarsArchive Citation}

Isaacowitz, Derek M.; Smith, Timothy B.; and Carstensen, Laura L., "Socioemotional selectivity and mental health among trauma survivors in old age" (2017). Faculty Publications. 2009.

https://scholarsarchive.byu.edu/facpub/2009 
Socioemotional Selectivity and Mental Health 1

Running head: SOCIAL LIVES OF TRAUMA SURVIVORS

Isaacowitz, D. M., Smith, T. B., \& Carstensen, L. L. (2003). Socioemotional selectivity and mental health among trauma survivors in old age. Ageing International, 28, 181-199.

Socioemotional selectivity and mental health among trauma survivors in old age

Derek M. Isaacowitz

Brandeis University

Timothy B. Smith

Brigham Young University

Laura L. Carstensen

Stanford University 


\begin{abstract}
Empirical tests of socioemotional selectivity theory support the contention that the developmental trend in adulthood to focus increasingly on fewer, but emotionally significant, social partners is associated positively with psychological well-being. Tenets of the theory, however, also suggest conditions in which selectivity could instead lead to an increase in negative emotional experiences. In particular, if the socioemotional world of the individual includes emotional distress, selective focus on emotions and close relationships may detract from rather than enhance well-being. In the current study, we examined selectivity and associated well-being in Holocaust survivors, JapaneseAmerican internment camp survivors, and comparably-aged people who lived through but did not experience major trauma during World War II. We predicted that selectivity would relate to positive mental health in all groups except the Holocaust survivors who, on average, experience elevated levels of negative affect and social networks that include other survivors also experiencing distress. Results generally supported these hypotheses, and are discussed in light of individual and group differences in socioemotional aging, as well as the implications for the generality of social developmental theories of adaptive functioning.
\end{abstract}


Socioemotional selectivity and mental health among trauma survivors in old age I don't think you could ever be normal. But I feel more normal than anybody else. . . I'm more normal because I know that everything is only for a short time. Other people think that it will be this way forever. I never trust things will last. Nothing is forever. I know I have it today. I am not sure I'll have it tomorrow. (Holocaust survivor, as quoted in Hass, 1995, p. 72)

This survivor, quoted in Aaron Hass' The Aftermath, illustrates well how Holocaust experiences may continue to affect time perspective and social relationships more than 50 years later. The quoted woman eloquently describes the psychological experience that accompanies full recognition of the finitude of life. Focus shifts from the future to the present. Value in life, for better or worse, is derived from the experience of the moment, not in what may or may not happen in the future. Although harrowing considered in the context of the horrific events of World War II, this poignant conception of life is also very common among the elderly and among younger people nearing the end of their lives (Carstensen \& Fredrickson, 1998; Fredrickson \& Carstensen, 1990). Interestingly, in normal aging, rather than lead to morose thoughts and emotional disengagement, just the opposite appears to occur. Boundaries on time appear to increase recognition of the preciousness of life (Carstensen, Isaacowitz, \& Charles, 1999).

According to socioemotional selectivity theory (Carstensen et al., 1999), when time is perceived as finite, individuals prioritize emotion-related goals over other possible goals, and choose to focus on familiar social partners over less familiar ones. Within these familiar relationships, individuals focus on the emotional quality of the relationships. This process is thought to be both fairly normative for individuals facing 
endings, and generally adaptive in these situations because it is associated with a deepening of emotional ties (Carstensen, 1992). Additionally, using a composite measure of social embededness including items related to social satisfaction, tenderness with social partners, and levels of social and emotional loneliness, Lang and Carstensen (1994) found selectivity to be related to greater feelings of social embededness (see also Lang, Staudinger \& Carstensen, 1998). More recently, Fung, Carstensen, \& Lang (2001) found that although small social networks are negatively correlated with happiness in young adults this is not the case in older adults.

To the extent that social selectivity allows people to proactively choose the supportive members of their social network, an extensive literature suggests that it likely facilitates interpersonal efficacy, good physical and mental health and positive states of well-being (Antonucci, 1989; Antonucci \& Knipscheer, 1990; Lang, 2001; Lansford, Sherman \& Antonucci, 1998). Social support also appears to directly reduce the risk of depression in the elderly (Holahan \& Holahan, 1987) and promote psychological recovery from trauma by reducing psychosocial isolation and buffering responses to stress (Loo, 1993). Nevertheless, no one disputes the fact that relationships also can be a source of significant distress (Pagel, Erdley, \& Becker, 1987; Rook, 1984). Thus, even though the pruning of social networks in late life such that only the closest social partners are retained and an emphasis on the emotional quality of those relationships is generally adaptive, there are cases where the same, normative selection processes may lead to negative outcomes, a point to which we now turn.

Based on earlier qualitative work on social relations among Holocaust survivors (e.g. Helmreich, 1992), we presumed that survivors, like most other older adults, focus on 
familiar social partners. However, findings on psychiatric distress in this population led us to consider whether a focus on emotionally significant social partners --when both the target individual and other members of their social networks are experiencing some degree of trauma-related distress--may be maladaptive. Our interest was in whether or not Holocaust survivors with highly "selected" networks experience more negative affect than those who have less "selected" social networks; if so, this set of circumstances may represent a special case in which selectivity does not lead to adaptive outcomes. Most relevant to the present study is research on marriage in older couples, which suggests that unhappily married older women suffer negative physical and mental health consequences (Carstensen, Levenson \& Gottman, 1995; see Carstensen, Graff, Levenson, \& Gottman, 1996, for a review; see also Rook, Dooley, \& Catalano, 1991). The authors interpret this as a possible negative effect of social selectivity. In other words, when selection leads to an emphasis on unhappy relationships in which distress is present, negative ramifications may logically follow.

Below we provide a thumbnail sketch of the literature on Holocaust survivors, attempt to link social selectivity in survivors to how they perceive the quality of their social relationships, and describe our experimental hypotheses.

$\underline{\text { Social and emotional functioning of Holocaust survivors }}$

Psychologists interested in quantitative, empirical analysis have largely ignored the social relations of Holocaust survivors. One exception is a large study of surviviors in Israel who were recruited either as part of a general study or who were targeted for a study of survivors, and found that those individuals recruited in the targeted study reported more positive affect than their peers recruited for a community sample (Shmotkin \& Lomranz, 1998). Most of the research conducted with Holocaust survivors 
has involved in-depth interviews, resulting in psychologically-oriented oral histories. Danieli (1997) summarizes quantitative research on survivors, concluding that elderly survivors have very small families and rather limited support networks. One sociological study of Holocaust survivors, Helmreich’s (1992) Against All Odds, asserts that Holocaust survivors have aged extremely well socially and psychologically. Based on extensive interviews, he concludes that survivors have close friendships, often with other survivors. Further, he states that survivors "are clearly more comfortable in their own ‘circle’” (p. 265). In Helmreich’s opinion, familiarity has characterized the social relations of survivors during the entirety of their post-Holocaust adult lives. His speculations are fully consistent with the theoretical position that social events that prime endings also lead to preferences for familiar social partners. In combination with the quote at the beginning of the paper, this body of work suggests that Holocaust survivors are highly selective in their social relationships and often invest in social relationships with other survivors. This research also suggests that relationships with children and close family members can be a source of distress for some survivors, as they can arouse feelings about relatives lost during the Holocaust.

Although empirical work on social relations among Holocaust survivors is scant (see, however, Kahana, Harel, \& Kahana, 1988, for an exception), there is substantial research demonstrating the presence of psychiatric distress in this population (Eaton, Sigal, \& Weinfeld, 1982; Kuch \& Cox, 1992; Marmar \& Horowitz, 1988; Robinson, Rapaport-Bar-Sever, \& Rapaport, 1994), with one study finding nearly half of a subject pool of survivors meeting DSM-III-R criteria for Post-Traumatic Stress Disorder (Kuch \& Cox, 1988). While there has been some debate about the existence of a particular 
“survivor syndrome,” it is difficult to dispute that considerable, persistent trauma-related distress, such as periodic nightmares, is pervasive among survivors.

Therefore, it seems likely that there is some negative affect present in the relationships of many Holocaust survivors, particularly those married to or close to other survivors. To the extent that Holocaust survivors both experience negative affect and interact primarily with other survivors, their relationships are likely marked by some degree of trauma-related negative affectivity. In other words, by associating primarily with close social partners, Holocaust survivors may be focusing their affective lives on other survivors. If they are all experiencing some degree of negative affect, and are focusing more on emotion in their relationships in line with selectivity theory, this might lead to an exacerbation of negative affect among socially selective Holocaust survivors.

Some survivors, however, choose not to focus on close relationships. A subgroup of Holocaust survivors appear anecdotally to have bucked the trend for older adults to focus on close social partners and instead have used their late life as an opportunity to expand their social circles - in particular, some devote a good deal of time and energy in their old age to telling the story of their experiences to strangers (see, for example, BarTur \& Levy-Shiff, 1994) or broader audiences by publishing personal memoirs (Zimering, 2001). While expanding social networks in old age may not be generally adaptive under other circumstances, we expect that those Holocaust survivors who choose to focus outward rather than being socially selective in old age may be effectively bypassing the negative affectivity of their close relationships, particularly those with other survivors. 
Social developmental theories have in the past paid relatively little attention to boundary conditions, such as the impact of nonnormative trauma on life-span socioemotional trajectories (cf., Seltzer \& Ryff, 1994). The current study aimed to begin to address socioemotional selectivity among Holocaust survivors and three other groups of older adults, with varying cultural backgrounds and trauma histories. While this may appear to be a specialized question about one particular theory, we believe that it has more general applications to understanding the multiple social trajectories taken throughout the life course by individuals with different life experiences. Furthermore, we believe that attempts to understand the psychological aftermath of stressful life events can benefit by links to established theoretical and testable frameworks. To that end, we hypothesized that people who survived life-threatening trauma early in life and who concentrate on close relationships with other survivors in later life suffer affectively rather than experience the more normative benefits prototypical of older people who have not experienced life-threatening trauma.

\section{Studying psychological adjustment of Holocaust survivors and other trauma survivors}

One problem involved in conducting quantitative research on Holocaust survivors involves determining appropriate comparison groups for analyses. In the current study, we make particular hypotheses concerning the socioemotional lives of Holocaust survivors in old age, related to their experience of trauma earlier in life and the quality of their affective lives and social relationships post-trauma. Because the operative mechanism in socioemotional selectivity theory is the perception of time, it was conceptually important to identify a group of survivors of non-genocidal trauma. Japanese-American internment camp survivors represent such a population. In compliance with Executive Order 9066, from 1942 until 1946, Japanese American 
residents of the western part of the United States were forcibly removed from their homes and relocated to internment camps (Nagata, 1993; for a more complete description of the internment, see Daniels, 1993). These American citizens endured a major traumatic event during the same historical period as the Holocaust. They lost their homes and businesses, and endured extremely harsh living conditions. However, genocide was not practiced.

While Loo (1993) suggests that some internment camp survivors may experience avoidance of the trauma, there is no systematic evidence of widespread continuing trauma-related distress among the survivors. Furthermore, based on her study of the children of internment camp survivors, Nagata (1993) concludes that the children feel their parents have coped quite well with their traumatic experience. Thus, Japanese American internment camp survivors are an interesting comparison group for Holocaust survivors: while their traumatic experiences occurred at the same time, they were different in nature and appear to have led to differential affective sequelae. Clearly, there are myriad cultural differences between Holocaust survivors and Japanese American internment camp survivors that have little or nothing to do with their traumatic experiences: nonetheless, we still felt a comparison would be informative regarding different post-trauma pathways of socioemotional functioning. Hypotheses

We expected our elderly Holocaust survivor participants to show different patterns of socioemotional functioning than our other groups of participants. In particular, we hypothesized that Holocaust survivors who focused more on close social partners would show more negative affect than those who were less selective. We also expected Holocaust survivors to have a more negative perception of their relationship quality, supporting the assertion that selectivity might be maladaptive given the surrounding circumstances described above. In the comparison groups, we expected 
social selectivity to be associated with less negative affect and perceived relationship quality to be relatively higher. Additionally, we were interested in whether self-reports of distress related to the trauma would exist only among Holocaust survivors, or whether it would also be found in the other subsamples.

Method

\section{$\underline{\text { Participants }}$}

Four subsamples were interviewed for this project $(\underline{N}=64, \underline{n}=16$ in each group): Jewish Holocaust survivors, Japanese American internment camp survivors, Americanborn Jews, and American-born Caucasian Protestants. In addition to internment camp survivors included for reasons outlined above, two other comparison samples were included in order to distinguish potential cultural and religious differences among groups from our theoretical interest in late life effects of genocidal trauma. One subsample comprised elderly Jews who had lived in the U.S. throughout the Holocaust, thus allowing us to disentangle religion from survivor status. Another subsample, Americanborn Protestant Caucasians, represented a group who lived through the war but was not a target of mass discrimination.

Because of the relatively small sample size, we elected to recruit only female participants for the study. All participants were 60 years of age or older (mean age $=72$, $\mathrm{SD}=5.82$ ), ranging from 61 to 86 years. All were U.S. citizens. Jewish women were slightly younger than the Japanese American internment camp survivors and the Caucasian Protestants , $\underline{\mathrm{F}}(3,60)=4.92, \underline{\mathrm{p}}<.01$ (linear contrast of Jewish participants vs. non-Jewish participants, $\mathrm{p}<.001$ ), and both survivor groups had significantly fewer years of education than the other two groups, $\underline{F}(3,60)=5.09, \underline{p}<.01$ (linear contrast of survivor vs. comparison groups, $\underline{\mathrm{p}}<.001$ ). Educational differences most likely reflected 
the fact that the traumatic events occurred during the high school and college years for most of the participants.

A participant was considered a Holocaust survivor if she was in a country occupied by the Nazis during some or all of the years 1939 to 1945, following Carmil \& Breznitz, 1991. While mass extermination did not begin until 1942 (Shanan, 1989), death was still omnipresent for Jews in the Nazi empire during the several preceding years. This was especially true following Kristallnacht, the Night of Broken Glass, which took place on November 9, 1938, and involved massive attacks on Jewish life in central Europe. Our sample of Holocaust survivors was quite diverse regarding wartime experiences: about half had been in concentration camps, while others had been in hiding or had been sent out of Germany on children's transport before they could be taken to camps. The comparison group of Jews consisted of age-matched American-born Jewish women. A participant was considered a Japanese American internment camp survivor if she was a Nisei who had spent some time in one of the ten camps run by the War Relocation Authority (WRA) to house Japanese Americans between 1942 and 1946.

The samples used in this study were located in a variety of ways, ranging from newspaper advertisements to announcements made to senior groups. Although several Holocaust survivors resided in New York, the majority of Holocaust survivors, and all members of the other groups, were residents of the San Francisco Bay Area. Our recruitment procedure was multifaceted: Holocaust survivors were recruited from survivors groups, newspaper ads, and Holocaust education centers. Japanese Americans were recruited through Buddhist churches and neighborhood associations. Americanborn Jews were recruited from newspaper ads and community centers. Protestant Caucasian participants were located by searching a name bank in the Stanford Life-span Development Laboratory that contains prospective participants recruited by a survey 
research form as well as newspaper ads. While these were certainly not randomly selected samples, we do believe that our diverse recruitment techniques provided relatively representative members of each targeted subgroup.

\section{Procedure}

Participants were interviewed individually in their homes, a convenient community center, or in the Stanford Psychology department. After providing informed consent and basic demographic information, each participant completed the questionnaires described below. Next, a structured interview was conducted concerning the participants' social relationships, data from which is not included in this report. The interview as a whole took between one hour and one and a half hours, and participants received a $\$ 10$ payment for their participation.

\section{$\underline{\text { Measures }}$}

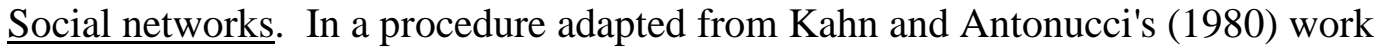
on social convoys, participants were asked to place people into one of three concentric circles based on whether they felt very close, close, or less close to each one. Unlike other studies using this measure (e.g. Antonucci \& Akiyama, 1991), we did not limit the number of names our participants could provide, so our total network numbers are higher than in some other studies using the same measure (see Lang et al., 1998, for another example of this modified use of the measure). Each person placed in one of the three circles was identified as a relative or a friend (non-relative). Participants were also asked to provide more detailed information about the people they had placed in the first circle (most close social partners): the person's relationship to the participant, their age, the frequency of contact, and whether they had known each other before World War II. Average emotional closeness, a measure of the participant's social selectivity, was calculated as the proportion of the social network made up of closest social partners 
(number of social partners in the first circle divided by total social network size). ${ }^{1}$ This proportion therefore describes the nature of the individual's social network, with high values reflecting more emotionally dense networks. To reduce skewness, these scores were then normalized with a square root transformation (see Fung et al., 2001 for another study using this construct). In addition to average emotional closeness of the network, a simple count of the total number of social partners in all circles was also used in some analyses.

Perceived relationship quality. Quality of interpersonal relationships was examined using the Content Analysis of Verbatim Explanations technique (CAVE; Schulman, Castillon, \& Seligman, 1989), which allows causal explanations to be extracted from transcripts of interviews and then coded on the dimensions of explanatory style. In this project, we used only the CAVE extraction technique, which involves identifying sections of transcripts in which individuals identify an event and then specify a cause for that event. Only clearly positive or negative events with a spontaneous cause were extracted using this method, which has previously yielded high levels of agreement among extractors (see Burns \& Seligman, 1989). A single coder, blind to the hypotheses of the study, was trained in the CAVE extraction technique and first extracted causal statements meeting CAVE criteria. Then, trained coders went through the extracted statements individually to insure they were unambiguously positive or negative. We used only those statements on which 2 coders agreed on valence in our analyses. Agreement between 2 coders for a subset of 80 such statements produced a Cohen’s kappa of .77.

Perceived quality in discussion of social relationships was calculated using the following equation, which is a monotonic function of the simple (\# positive)/(\# negative) 
ratio but eliminates the problem of zero responses of either type: (\#positive \#negative)/(\#positive + \#negative).

Depressive symptoms. We assessed negative affect using the 13-item short form of the Beck Depression Inventory, on which higher scores indicate the presence of greater levels of negative affect and depressive symptoms (Beck, Rial, \& Rickels, 1974). Coefficient alpha for the BDI was .77.

Post-Traumatic Stress Disorder (PTSD) and the salience of the trauma in everyday life. The Revised Impact of Event Scale (Horowitz et al., 1979), which includes 15 items of subjective distress commonly reported among people seeking treatment for Post-Traumatic Stress Disorder (PTSD), was used to assess PTSD symptoms specifically related to the participants' experiences during the time of World War II. Participants rate the frequency with which they experience certain thoughts, feelings and behaviors related to these experiences (such as nightmares). This measure was used as a proxy for the salience of the traumatic event in the everyday life of the person rather than a diagnostic tool. Holocaust survivors and Japanese American internment camp survivors were reminded in the instructions to consider the effects of the specific wartime event, while comparison group participants were reminded simply that during World War II they had survived a difficult time in history. Aside from this first sentence of the instructions, the rest of the form was identical for all groups. Coefficient alpha for this scale was .92 .

\section{Results}

\section{Differences among the subgroups}

No subgroup differences emerged on average emotional closeness of social networks, or depressive symptoms. We conducted a group comparison on the measure of 
trauma salience, or how often the subject has intrusive or avoidant symptoms related to the traumatic event in their everyday life. The main effect for group differences was significant, $\underline{\mathrm{F}}(3,60)=4.91, \underline{\mathrm{p}}<.01$. Holocaust survivors had the highest mean levels, followed not by the other trauma survivor subsample but rather by the American-born Jews. Next came Japanese-American internment camp survivors, and finally the American-born Protestant subsample. These mean levels are shown in Table 1.

A planned linear contrast showed that Holocaust survivors had higher trauma salience scores than the other groups, $\mathrm{p}<.01$. This confirms the important point that Holocaust survivors can be expected to be experiencing some degree of trauma-related distress in their everyday lives and that they are the subsample most clearly experiencing distress.

While there were no differences among the subsamples on the average emotional closeness measure (which is indeed the primary measure of social selectivity), there was a difference among subsamples in total social networks, $\underline{F}(3,60)=2.79, \underline{p}<.05$. As shown in Table 1, Holocaust survivors had the smallest social network size, followed by American-born Jews, Japanese American internment camp survivors and American-born Protestants. The linear contrast of Holocaust survivors versus others did not reach statistical significance.

As shown in Table 1, there were group differences in level of perceived relationship quality, $\underline{\mathrm{F}}(3,53)=5.48, \underline{\mathrm{p}}<.01 .^{2} \quad$ A planned linear contrast revealed that the comparison groups demonstrated significantly higher perceived relationship quality than did the survivors, $\underline{\mathrm{t}}(53)=-3.00, \underline{\mathrm{p}}<.01$. However, Table 2 shows that the Protestant Caucasian group expressed the most positive perceived relationship quality; many of them did not make any negative explanatory statements during the interview. Japanese 
American internment camp survivors were more balanced, though still slightly favoring positive statements. Holocaust survivors were nearly balanced in their use of positive and negative statements.

\section{The adaptiveness of social selectivity}

The primary test of the differential effects of socioemotional selectivity among elderly trauma survivors involved comparing the correlations between average emotional closeness (the primary measure of socioemotional selectivity) and negative affect (as measured by the BDI) in the different subsamples. Based on our findings that Holocaust survivors were the only subsample with significant distress present and the most negative in their perceived relationship quality, we expected that social selectivity would exacerbate distress among this group, but would protect against the negative effects of stress in the other subsamples who were not experiencing significant trauma-related distress.

In the entire sample, average emotional closeness and BDI score were uncorrelated ( $\underline{\mathrm{r}}=.02$, n.s.). However, consistent with hypotheses, this lack of correlation masked interesting differences among the four subsamples. The four groups had quite different correlations between the two variables. The correlation for Holocaust survivors was .38, while it was .05 for American-born Jews, -.50 for Japanese-American internment camp survivors, and -.20 for American-born Protestants. Note that a negative correlation means that more emotionally dense social networks are related to lower rates of negative affect, which would be expected normatively from research on social selectivity. A positive correlation indicates that emotionally dense social networks may be affectively maladaptive, as they are associated with higher levels of depressive symptoms. The rank order of these correlations is similar to the rank order of traumarelated distress scores shown in Table 1. 
Tests for differences between correlations. Although only the correlation for the Japanese American subsample was significantly different than zero, given small subsample sizes, the correlations were compared to one another using Fisher ztransformations. These comparisons are informative because the correlations for the subsamples are generally in the predicted directions, with Holocaust survivors showing maladaptive responses to higher average emotional closeness, while the other subsamples have negative or no associations.

The initial test involved the comparison of the Holocaust survivors to members of the other samples, to disentangle the effects of this trauma characterized specifically by genocide. This test seems acceptable despite the different sample sizes (16 vs. 48) in that it is very conservative. One-sided z-tests were used because our hypothesis was that Holocaust survivors show a positive correlation between the two variables, whereas the other subsample correlations should be zero or negative. We also used partial correlations controlling for sample differences in age and education. The Fisher z-test found significant differences between the Holocaust survivors $(\mathrm{pr}=.43)$ and the other three groups $(\underline{\mathrm{pr}}=-.09), \underline{\mathrm{z}}=1.75, \underline{\mathrm{p}}<.05$.

The Holocaust survivor subsample was not significantly different than the other Jewish subsample. However, the Holocaust survivors and Japanese American internment camp survivors did differ from each other significantly, $\underline{z}=2.42, \underline{p}<.01$.

\section{$\underline{\text { Trauma salience }}$}

We also investigated whether trauma salience was a better predictor of negative outcomes than group membership. While average emotional closeness and negative affect were uncorrelated in the whole sample as described above, trauma salience was positively correlated with both average emotional closeness $(\underline{r}=.26, \underline{p}<.05)$ and negative affect $(\underline{r}=.32, \underline{p}<.01)$. In other words, participants in all subsamples who had 
more intrusive and avoidant symptoms related to the events of World War II in their everyday lives also tended to have more selected social networks and to have higher rates of depressive symptoms.

\section{Discussion}

Considerable evidence exists for a developmental trend in adulthood to gradually narrow social networks such that by later life social networks are heavily concentrated with emotionally close social partners (Carstensen, 1992; 1993). This process has been associated with benefits to quality of life among older adults in a diverse range of populations (Lang, et al., 1994; Fung, et al., 2001). Socioemotional selectivity theory contends that the approach of endings, particularly the approach to the end of life that old age heralds, provokes a reorganization of goal constellations. Emotionally meaningful goals are prioritized over other goals. For most people, close relationships are the most meaningful arenas of life (Carstensen et al., 1999).

In the present study, we considered a special case, also consistent with the theory, in which benefits may not arise from a focus on closest relations and emotional goals: when distressed individuals selectively associate with other distressed individuals. For theoretical reasons, we focused on Holocaust survivors because they experienced a trauma early in life that primed a sense of mortality and who, according to the literature, disproportionately associate with other survivors. For practical reasons, we focused on survivors because too little is known about the long-term effects of one of the most horrific genocides in human history. Our question was whether Holocaust survivors experience similar benefits of selectivity as other groups show. Our hypothesis was that they would not.

Results provided support for this hypothesis. Social selectivity seems to be maladaptive when both of two conditions are met: the first is related to this study's data, 
and the second is admittedly more speculative. First, if there is distress present in the person's life generally; and second, if the person's close social partners are likely to also be experiencing some degree of distress. Focus on emotion in these close relationships apparently exacerbates intrapsychic distress. The finding that Holocaust survivors have both the most PTSD symptoms in their current life as well as relatively negative perceived relationship quality supports this contention.

According to qualitative accounts of the social relationships of Holocaust survivors (e.g. Helmreich, 1992), survivors’ networks tend to include other survivors. This was true in our sample as well. Nine of the 16 Holocaust survivors named at least one other survivor among their closest social partners, especially notable considering the age of the participants and the fact that many survivors have already passed away. Additionally, seven of the 16 Holocaust survivors had married other Holocaust survivors. Thus, this particular group of older adults not only suffer as individuals, as indicated by their elevated levels of PTSD symptoms; the most important people in their lives are likely to be similarly distressed.

The lack of a significant difference between correlations of selectivity and negative affect in both groups of Jewish participants raises the possibility that the potentially maladaptive nature of emotion-focus may be an artifact of cultural and religious differences. Certainly, ethnic styles among American Jews regardless of birth country have been noted, such as a tendency to communicate about pain rather than keeping it to one's self (Zborowski, 1969). However, the correlation between selectivity and negative affect in American-born Jews is near zero ( $\underline{r}=.05)$, and in a larger sample would likely be significantly different from the correlation between selectivity and negative affect among Jewish Holocaust survivors ( $\underline{r}=.38)$.

As suggested in earlier studies, Japanese Americans who were interned in the 
United States during WWII do not show similar long-term effects of trauma. On the contrary, a focus on close social partners was especially adaptive among members of the Japanese American subsample. Consistent with our argument, interviews conducted with internment camp survivors suggests that Japanese Americans expanded their social networks outward after the internment rather than selecting them more closely (Nagata, 1993). Our measures of trauma salience suggest that Japanese internment camp survivors experience relatively little distress in their present lives stemming from the traumatic experiences during World War II. While this may in part result from cultural factors including a reluctance to admit to psychological distress, the findings do fit nicely with an emerging position that selectivity is maladaptive only when there is distress present in both individuals and those people with whom they have close social ties.

Our findings also give credence to anecdotal reports that Holocaust survivors who expanded their networks and focused on sharing their stories with others (often complete strangers, such as school groups) appear to experience relatively less distress and negative affect in their old age. That is, survivors who spend time sharing their Holocaust experiences with others, and do not just focus on their closest social partners, are doing relatively better in old age compared with those who keep the story to themselves and their close social partners. Interestingly, this result can be seen as consistent with Shmotkin \& Lomranz’s (1998) findings that Holocaust survivors recruited specifically for research on survivors, who the authors assume may have “higher social involvement and readiness to advance Holocaust-related research” (p. 144), report more positive affect than their peers recruited from a community sample, not targeted specifically at survivors. Such findings, of course, are also consistent with research by Pennebaker and colleagues (1997) showing that talking about trauma reduces its negative after-effects. Pennebaker, Barger and Tiebout (1989) found specifically that 
Holocaust survivors who disclosed their experiences to strangers were in better physical health 14 months later. While sociological work suggests that Jews are more likely in general to speak openly about their pain than are member of other ethnic groups (Zborowski, 1969), the psychological literature maintains that individual differences may still exist favoring Jewish disclosers over those who disclose less.

Our sample of Holocaust survivors had the smallest social networks of the 4 samples in the study. This is likely a result of the enormous losses they experienced in the Holocaust (Danieli, 1997). Some Holocaust survivors may have not replaced lost members of their social networks. Loss and continued mourning may thus explain the negative affect among those Holocaust survivors with more selected social networks. It is worth noting, however, that one feature of the social networks of participants with high levels of trauma salience, regardless of group membership, is that they tended to be smaller in total size. While total network size was not predictive of affective outcomes, it raises the possibility that people with many thoughts and feelings about trauma may be selected out of other people's social networks. Additionally, trauma salience was correlated with both more selected social networks and more depressive symptoms, suggesting that is in the particular life context in which trauma continues to play a significant role in an individual's psychological life that selectivity may be linked to negative affect.

\section{$\underline{\text { Limitations }}$}

A major limitation of this study involves the small, non-representative subsamples. The small sample size necessarily makes our findings and conclusions tentative, and they await replication in a larger sample before they can be treated with greater confidence. There was some variation even among the Holocaust survivors, as some had been in concentration camps, while others had been in hiding. A second 
limitation concerns the imperfect comparison groups we included. While the ideal comparison group for Holocaust survivors would be comprised of European-born Jewish women who emigrated to the United States before the Holocaust (before 1939, by the above standards), there is simply not an adequate, accessible population meeting these criteria in the San Francisco Bay Area. Although these are the very women described by Myerhoff in Number Our Days (1978), her work was done in the 1970s. This population has become increasingly small over time. There are certainly cultural differences between the two groups of Jewish women, even though they have lived in the same culture now for at least 40 years or so. Participants in both groups were very young before World War II, so differences in experiences during the war should be more salient than differences in pre-war experiences. We also acknowledge that there is a migration confound, as the Holocaust survivors are the only group who moved from one continent to another. However, many of the Japanese American participants also moved rather large distances during and after the internment. A perfect comparison group for the Japanese American internment camp survivors would consist of non-interned Nisei women but such a group exists in adequate numbers only in Hawaii.

We included a subsample of Protestant Caucasian Americans for comparison purposes with other groups, but also to ensure the replication of basic socioemotional selectivity findings. As expected, this subsample (and indeed all subsamples) had average emotional closeness scores that were highly similar to those found in larger studies of Caucasian populations (Fung et al., 2001). Thus, while small, we contend that our subsamples were the best possible theoretically given pragmatic constraints, allowing for control of "survivorship” in general as well as for Jewish religion and culture.

One final limitation is that we cannot know for sure whether our less selective individuals are actively seeking out new social relationships in late life, actually have 
more diffuse emotional relationships, or show low levels of average emotional closeness for some other reason entirely. Future research is needed to clarify how individuals end up in old age with relatively nonselected social networks.

\section{$\underline{\text { Practical applications and implications }}$}

The finding that different patterns of socioemotional choices may be differentially adaptive depending on life history of trauma has direct implications for the planning and provision of social services to diverse groups of older individuals. The idea that some type of social interaction - whether it be meeting new people, engaging in reminiscence groups, or spending time with close friends - is a "must” for all older individuals, regardless of their unique background, is clearly a vast oversimplification. Although socioemotional selectivity theory posits that that older individuals, on average, prefer to interact with close social partners, it presumes that for most people such interactions are largely affectively positive. Indeed, in the larger population, this is the case. Also reasoning from the theory, in cases where interactions with close social partners are affectively negative, it suggests outcomes will be relatively less positive. In this study, we present the first empirical evidence that this is the case. At a practical level, it means that blanket recommendations that older individuals focus on those closest to them should be tempered. Rather, these results point to the need for an awareness of history-graded and nonnormative influences before considering what the optimal social environment may be for an older individual, and whether there are obstacles to that individual achieving her optimal social context.

\section{$\underline{\text { Conclusions }}$}

Perhaps the most important implication of this study is that social selectivity and emotion focus can be a buffer against the negative effects of stress or a potential cause of negative affect among older adults depending on the nature of the stressful experiences 
they have (or have not) endured during their lives and the social partners they select. Consistent with socioemotional selectivity's normative hypotheses, in most cases focus on familiar social partners by older adults is unrelated or negatively correlated with depressive symptoms. However, in situations such as having survived a trauma after which survivors can be expected to show some ongoing signs of trauma-related distress, selectivity may be maladaptive. These findings highlight the importance of considering the multiple trajectories individuals traverse as they grow older, and the influence this heterogeneity may have for developmental theories of adaptive functioning (Magai, 2001). For example, the findings could inform theory and research on the buffering effect of social relationships on distress (Antonucci \& Knipscheer, 1990), as well as theories that explicate attributional processes following trauma (Frazier, 1990). Most generally, these results suggest the need for an appreciation of the diversity of social worlds experienced by older individuals, as well as how critical it is to understand the adaptive function these social worlds may serve in light of unique life experiences. 


\section{References}

Antonucci, T.C. (1989). Social support influences on the disease process. In L.L. Carstensen \& J.M. Neale (Eds.), Mechanisms of psychological influence on physical health (pp. 23-41). New York: Plenum Press.

Antonucci, T.C. \& Akiyama, H. (1991). Convoys of social support: Generational Issues. Marriage and Family Review, 16, 103-123.

Antonucci, T.C. \& Knipscheer, K.C.P.M. (1990). Social network research: Review and perspectives. In K.C.P.M. Knipscheer \& T.C. Antonucci (Eds.), Social network research (pp. 161-173). Amsterdam: Swets \& Zeitlinger.

Bar-Tur, L., \& Levy-Shiff, R. (1994). Holocaust review and bearing witness as a coping mechanism of an elderly Holocaust survivor. Clinical Gerontologist, 14,5-16.

Beck, A.T., Rial, W.Y., \& Rickels, K. (1974). Short form of Depression Inventory: Cross-validation. Psychological Reports, 34, 1184-1186.

Burns, M. and Seligman, M.E.P. (1989). Explanatory style across the lifespan: Evidence for stability over 52 years. Journal of Personality and Social Psychology, 56, 118-124.

Carmil, D. \& Breznitz, S. (1991). Personal trauma and world view - Are extremely stressful experiences related to political attitudes, religious beliefs, and future orientation? Journal of Traumatic Stress, 4, 393-405.

Carstensen, L.L. (1992). Social and emotional patterns in adulthood: Support for socioemotional selectivity theory. Psychology and Aging, 7, 331-338.

Carstensen, L.L. (1993). Motivation for social contact across the life span: A theory of socioemotional selectivity. In J. Jacobs (Ed.), Nebraska symposium on motivation: Vol. 40, Developmental perspectives on motivation (pp. 209-254). 
Lincoln: University of Nebraska Press.

Carstensen, L.L. \& Fredrickson, B.L. (1998). Socioemotional selectivity in healthy older and younger people living with the Human Immunodeficiency Virus (HIV): The centrality of emotion when the future is constrained. Health Psychology, 17, 494503.

Carstensen, L.L., Graff, J., Levenson, R.W., \& Gottman, J.M. (1996). Affect in intimate relationships: The developmental course of marriage. In C. Magai \& S. McFadden (Eds.), Handbook of Emotion, Adult Development, and Aging. Orlando, FL: Academic Press.

Carstensen, L.L., Isaacowitz, D.M., \& Charles, S.T. (1999). Taking time seriously: A theory of socioemotional selectivity. American Psychologist, 54, 155-181.

Carstensen, L.L., Levenson, R.W., \& Gottman, J.M. (1995). Unhappy Marriages in Late Life. Paper presented in symposium on Negative Aspects of Social Relations in Later Life at the Gerontological Society of America Annual Scientific Meeting, Los Angeles.

Danieli, Y. (1997). As survivors age: An overview. Journal of Geriatric Psychiatry, 30, $9-26$.

Daniels, R. (1993). Prisoners without trial: Japanese Americans in World War II. New York: Hill and Wang.

Eaton, W.W., Sigal, J.J., \& Weinfeld, M. (1982). Impairment in Holocaust survivors after 33 years: Data from an unbiased community sample. American Journal of Psychiatry, 139, 773-777.

Frazier, P. A. (1990). Victim attributions and post-rape trauma. Journal of Personality 
and Social Psychology, 59, 298-304.

Fredrickson, B.L. \& Carstensen, L.L. (1990). Choosing social partners: How old age and anticipated endings make people more selective. Psychology and Aging, 5, 335347.

Fung, H., Lang, F.R., \& Carstensen, L.L. (2001). Age-related patterns in social relationships among European Americans and African Americans: Implications for socioemotional selectivity across the lifespan. International Journal of Aging and Human Development, 52, 185-206.

Hass, A. (1995). The aftermath: Living with the Holocaust. Cambridge: Cambridge University Press.

Helmreich, W. (1992). Against all odds: Holocaust survivors and the successful lives they made in America. New York: Simon and Schuster.

Holahan, C.K. \& Holahan, C.J. (1987). Self-efficacy, social support, and depression in aging: A longitudinal analysis. Journal of Gerontology, 42, 65-68.

Horowitz, M., Wilner, N., \& Alvarez, W. (1979). Impact of event scale: A measure of subjective stress. Psychosomatic Medicine, 41, 209-218.

Kahana, B., Harel, Z., \& Kahana, E. (1988). Predictors of psychological well-being among survivors of the Holocaust. In J.P. Wilson, Z. Harel, \& B. Kahana (Eds.), Human adaptation to extreme stress: From the Holocaust to Vietnam (pp. 171192). New York: Plenum Press.

Kahn, R.L. \& Antonucci, T.C. (1980). Convoys over the life course: Attachment, roles and social support. In P.B. Baltes \& O.G. Brim (Eds.), Life-span development and behavior (Vol. 3) (pp. 253-286). San Diego: Academic Press. 
Kuch, K. \& Cox, B.J. (1992). Symptoms of PTSD in 124 survivors of the Holocaust. American Journal of Psychiatry, 149, 337-340.

Lang, F.L. (2001). Regulation of social relationships in later adulthood. Journal of Gerontology: Psychological Sciences, 56B, P321-P326.

Lang, F.L. \& Carstensen. L.L. (1994). Close emotional relationships in late life: Further support for proactive aging in the social domain. Psychology and Aging, 9, 315324.

Lang, F.L., Staudinger, U.M., \& Carstensen, L.L. (1998). Socioemotional selectivity: How personality and social context do (and do not) make a difference. Journal of Gerontology: Psychological Sciences, 53B, P21-P30.

Lansford, J. E., Sherman, A. M. \& Antonucci, T. C. (1998). Satisfaction with social networks: An examination of socioemotional selectivity theory across cohorts. Psychology and Aging, 13, 544-552.

Loo, C.M. (1993). An integrative-sequential treatment model for Posttraumatic Stress Disorder: A case study of the Japanese American internment and redress. Clinical Psychology Review, 13, 89-117.

Magai, C. (November, 2001). Socioemotional profiles and physical resiliency in late life. In K. L. Fingerman (Chair), Complexities of socioemotional experience in adulthood. A symposium presented at the Gerontological Society of America, Chicago.

Marmar, C.R. \& Horowitz, M.J. (1988). Diagnosis and phase-oriented treatment of PostTraumatic Stress Disorder. In J.P. Wilson, Z. Harel, \& B. Kahana (Eds.), Human adaptation to extreme stress: From the Holocaust to Vietnam (pp. 81-104). New 
York: Plenum Press.

Myerhoff, B. (1978). Number our days. New York: Simon and Schuster.

Nagata, D.K. (1993). Legacy of injustice: Exploring the cross-generational impact of the Japanese American internment. New York: Plenum Press.

Pagel, M.D., Erdly, W.W., \& Becker, J. (1987). Social support: We get by with (and in spite of) a little help from our friends. Journal of Personality and Social Psychology, 53, 793-804.

Pennebaker, J.W. (1997). Opening up: The healing power of expressing emotions. New York: The Guilford Press.

Pennebaker. J.W., Barger, S.D., \& Tiebout, J. (1989). Disclosure of traumas and health among Holocaust survivors. Psychosomatic Medicine, 51, 577-589.

Robinson, S., Rapaport-Bar-Sever, M., \& Rapaport, J. (1994). The present state of people who survived the Holocaust as children. Acta Psychiatrica Scandinavica, 89, 242-245.

Rook, K.S. (1984). The negative side of social interaction: Impact on psychological wellbeing. Journal of Personality and Social Psychology, 46, 1097-1108.

Rook, K., Dooley, D., \& Catalano, R. (1991). Stress transmission: The effects of husbands' job stressors on the emotional health of their wives. Journal of Marriage and the Family, 53, 165-177.

Schulman, P., Castellon, C., and Seligman, M.E.P. (1989). Assessing explanatory style: The Content Analysis of Verbatim Explanations and the Attributional Style Questionnaire. Behaviour Research and Therapy, 27, 505-512.

Seltzer, M.M., \& Ryff, C.D. (1994). Parenting across the life span: The normatibe and 
nonnormative cases. In D.L. Featherman, R.M. Lerner, \& M. Perlmutter (Eds.), Life-Span Development and Behavior, Vol. 12 (pp. 1-40). Hillsdale, NJ: Erlbaum. Shanan, J. (1989). Surviving the survivors: Late personality development of Jewish Holocaust Survivors. International Journal of Mental Health, 17, 42-71.

Shmotkin, D., \& Lomranz, J. (1998). Subjective well-being among Holocaust survivors: An examination of overlooked differentiations. Journal of Personality and Social Psychology, 75, 141-155.

Zborowski, M. (1969). People in pain. San Francisco: Jossey-Bass Inc., Publishers.

Zimering. S. (2001). Hiding in the open: A Holocaust memoir. St. Cloud, MN: North Star Press of St. Cloud, Inc. 
Socioemotional Selectivity and Mental Health 31

Author Note

This research was supported by an Undergraduate Research Grant from Stanford

University and a National Science Foundation Graduate Research Fellowship to the first author, and by NIA grant RO1-8816 to the third author. 


\section{Footnotes}

1"Average emotional closeness" is an index of the same variable as "emotional density" (e.g. Fung et al., 2001).

${ }^{2}$ Several participants were not included in these analyses because of equipment malfunction that prevented their interview from being transcribed: the available sample consisted of 16 Holocaust survivors, 14 Japanese American internment camp survivors, 13 American-born Jews, and 14 Protestant Caucasians. 
Table 1. Group means and SDs

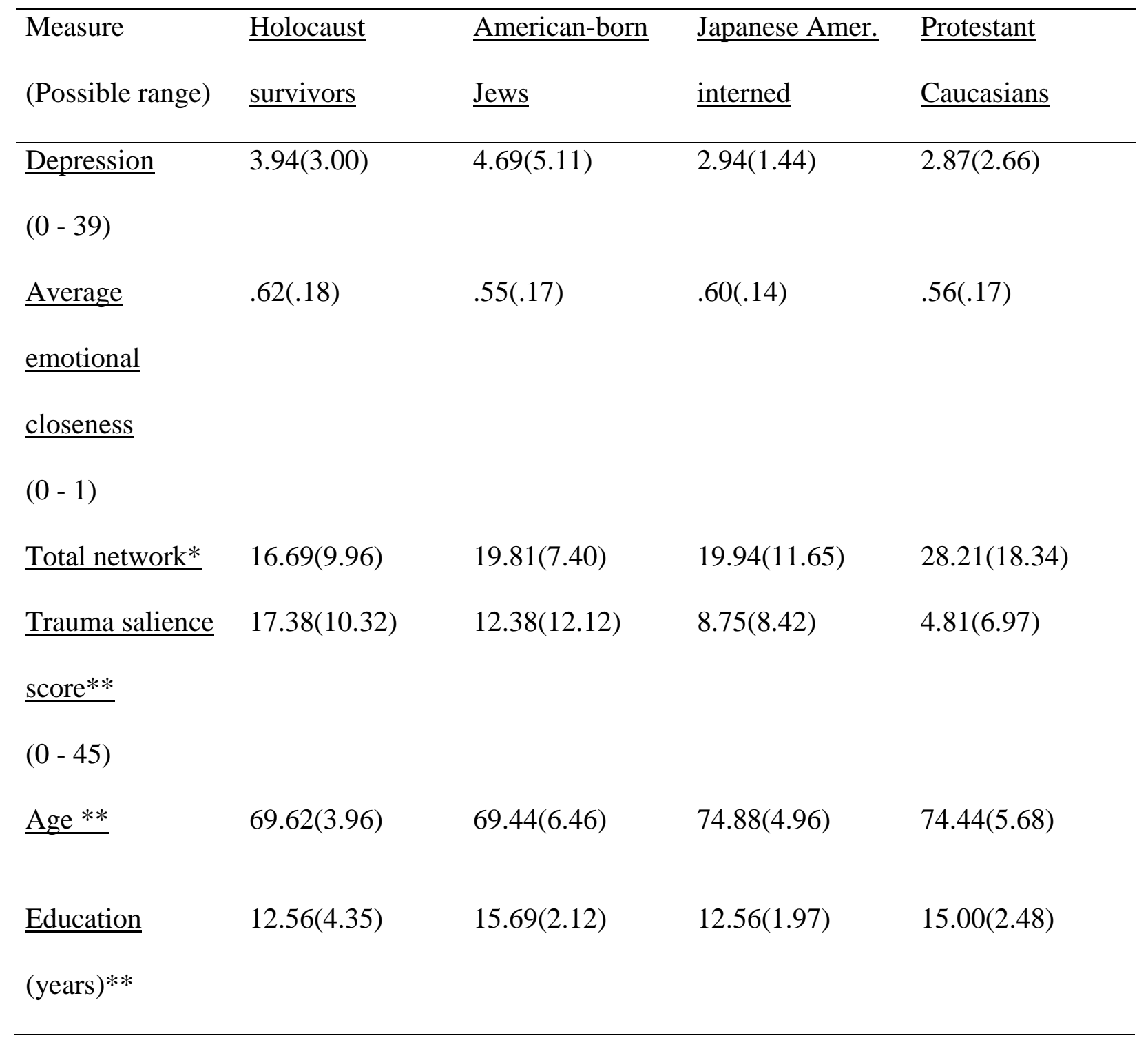

Omnibus effect of group: ${ }^{*} \mathrm{p}<.05 * * \mathrm{p}<.01$ 
Table 2. Perceived relationship quality, as measured by ratio of positive to negative statements about relationships.

\begin{tabular}{ll}
\hline Group & $\underline{\text { Positive to Negative Ratio (SD) }}$ \\
\hline Holocaust survivors & $.09(.56)$ \\
Japanese American internment camp survivors & $.12(.80)$ \\
American-born Jews & $.27(.48)$ \\
American-born Protestant Caucasians & $.84(.33)$ \\
\hline Note: Ratio can range from +1 (all positive statements) to -1 (all negative statements)
\end{tabular}


Biographical Statements:

Derek M. Isaacowitz is an Assistant Professor of Psychology at Brandeis University. He completed his undergraduate work at Stanford University and his Ph.D. at the University of Pennsylvania. His research focuses on emotion in adulthood and old age.

Timothy B. Smith is an Associate Professor of Counseling Psychology at Brigham Young University. He is currently the editor of the Journal of College Counseling and the Chair of the Council of Journal Editors for the American Counseling Association. His publications are mostly in the areas of multicultural psychology and the psychology of religion.

Laura L. Carstensen is Professor of Psychology at Stanford University. She has published extensively about emotional, cognitive and motivational changes with age and formulated socioemotional selectivity theory. Dr. Carstensen is currently Chair of the National Academy of Sciences Committee on Social Psychology and Aging. In 1998, she received Stanford Universitys Deans Award for Distinguished Teaching. 